\title{
PRE-ANESTHETIC MEDICATIONS IN PATIENTS UNDERGOING EXPLORATORY LAPAROTOMY: RESULTS OF A CROSS-SECTIONAL STUDY
}

\author{
ANANT PATIL ${ }^{1}$, MADHURI KULKARNI ${ }^{2}$ \\ ${ }^{1}$ Department of Pharmacology, Dr. DY Patil Medical College, Navi Mumbai, Maharashtra, India. ${ }^{2}$ Department of Pharmacology, Government \\ Medical College, Aurangabad, Maharashtra, India. Email: anantdpatil@gmail.com \\ Received: 21 October 2017, Revised and Accepted: 08 December 2017
}

\section{ABSTRACT}

Objective: The objective of this study was to understand the pattern of pre-anesthetic medication utilization in patients undergoing exploratory laparotomy.

Methods: In this cross-sectional study, we reviewed the records of patients who underwent exploratory laparotomy under general anesthesia. Descriptive data of the pre-anesthetic medications used in the patients are presented.

Results: A total of 49 patients with mean \pm SD age of $65.85 \pm 34.15$ years were included in the study. The study population was dominated by male patients (65.85\%). Two major indications for exploratory laparotomy in the study population were perforation peritonitis 19 (38.77\%) and intestinal obstruction 9 (18.37\%). Ondansetron was used in all patients. Metoclopramide and ranitidine were used in 48 (98\%) patients each. Midazolam was given to $43(87.8 \%)$ patients. A total of $41(83.7 \%)$ patients received anticholinergic agent glycopyrrolate or atropine. Pentazocine and fentanyl were used in 39 (79.6\%) and 10 (20.4\%) patients, respectively.

Conclusion: Ondansetron, metoclopramide, ranitidine, midazolam, glycopyrrolate, and pentazocine were the major pre-anesthetic medications in patients undergoing exploratory laparotomy. Glycopyrrolate was the most preferred anticholinergic agent.

Keywords: Drug utilization, Exploratory laparotomy, Pre-anesthetic medications.

(C) 2018 The Authors. Published by Innovare Academic Sciences Pvt Ltd. This is an open access article under the CC BY license (http://creativecommons. org/licenses/by/4. 0/) DOI: http://dx.doi.org/10.22159/ajpcr.2018.v11i3.23229

\section{INTRODUCTION}

Drug utilization studies are useful for ensuring regular availability of routinely required medicines, especially in large multi-specialty clinical setups. Such studies are also important for ensuring rational use of medicines, understanding drug interactions and reducing the risk of adverse events. There are limited drug utilization studies showing a pattern of pre-anesthetic medicine usage in Indian settings.

Anxiety, pain and risk of post-operative complications are major concerns in patients undergoing surgery under general anesthesia. Pre-anesthetic medications are administered for prevention of anxiety and pain, facilitate operative procedure, and minimize the risk of complications [1]. Commonly used pre-anesthetic medications include benzodiazepines [2-4], anticholinergic agents [1,5-7], pentazocine [8,9], opioids [1], 5-HT3 antagonists [10], and metoclopramide and ranitidine [11]. Recently, we reported drug utilization pattern of pre-anesthetic medicines in patients undergoing major surgeries under general anesthesia [12]. The pattern of pre-anesthetic medications may differ based on the type of surgery, anesthetic agent and profile of the patient.

\section{Objective}

The objective of this study was to understand utilization pattern of preanesthetic medications in patients undergoing exploratory laparotomy.

\section{METHODS}

This cross-sectional study was performed in a tertiary care hospital from Maharashtra. We reviewed utilization pattern of pre-anesthetic medications in patients from all age groups who underwent exploratory laparotomy under general anesthesia. Demographic data, indication for exploratory laparotomy and details of pre-anesthetic medications were recorded. Approval from the Institutional Ethics Committee was obtained before initiating the study.
Statistical analysis

Categorical variables are presented as number and percentages whereas continuous variables are described as mean and standard deviations.

\section{RESULTS}

A total of 49 patients were included. The mean \pm SD age of the patients was $65.85 \pm 34.15$ years. The age of patients ranged from 3 days to 76 years. The study included male patients predominantly (Table 1).

The number and percentages of indications for surgeries are shown in Table 2 .

Two major indications for exploratory laparotomy were perforation peritonitis 19 (38.77) and intestinal obstruction 9 (18.37) (Table 2). Data for $2(4.08 \%)$ patients were missing.

Ondansetron was used in all patients whereas metoclopramide and ranitidine were used in 48 (98\%) patients each. Midazolam was used in $43(87.8 \%)$ patients. Out of these, $41(95.3 \%)$ patients received midazolam $1 \mathrm{mg}$ whereas only $2(4.7 \%)$ patients received midazolam $0.5 \mathrm{mg}$. A total of $41(83.7 \%)$ patients received anticholinergic agent glycopyrrolate or atropine. Pentazocine and fentanyl were used in $39(79.6 \%)$ and 10 (20.4\%) patients, respectively (Fig. 1).

Table 1: Baseline characteristics

\begin{tabular}{ll}
\hline Parameter & Result $(\mathbf{n = 4 9 )}$ \\
\hline Mean $( \pm$ SD) age in years $(n=35)$ & $65.85 \pm 34.15$ \\
Age range & 3 days to 76 years \\
Male $n(\%)$ & $27(65.85)$ \\
Female $n(\%)$ & $14(34.15)$ \\
\hline
\end{tabular}


Table 2: Indications for exploratory laparotomy

\begin{tabular}{|c|c|c|c|}
\hline Condition & n (\%) & Condition & n (\%) \\
\hline $\begin{array}{l}\text { Perforation peritonitis (alone, with pulmonary tuberculosis, } \\
\text { strangulated incisional hernia, secondary to appendicitis, with } \\
\text { ileal perforation, anastomosis leak, urinary bladder rupture) }\end{array}$ & 19 (38.77) & Penetrating injury & $1(2.04)$ \\
\hline Duodenal perforation with peritonitis & $1(2.04)$ & Renal cell carcinoma & $1(2.04)$ \\
\hline Congenital diaphragmatic hernia & $1(2.04)$ & Malignant ovarian tumor & $1(2.04)$ \\
\hline Bowel gangrene & $1(2.04)$ & Colon cancer & $2(4.08)$ \\
\hline Peritonitis (alone or with small bowel obstruction) & $2(4.08)$ & $\begin{array}{l}\text { Intestinal obstruction (alone, with gangrene, with } \\
\text { ovarian tumor) }\end{array}$ & $9(18.37)$ \\
\hline Blunt trauma to abdomen & $2(4.08)$ & Blunt abdominal trauma with liver laceration & $1(2.04)$ \\
\hline Gastroschisis & $2(4.08)$ & Small bowel gangrene with peritonitis & $1(2.04)$ \\
\hline Appendicitis with perforation & $2(4.08)$ & Stab injury to abdomen & $1(2.04)$ \\
\hline
\end{tabular}

Glycopyrrolate was given to 33 (67.3\%) patients. Eight (16.3\%) patients received atropine. In other $8(16.3 \%)$ patients anticholinergic agent was not used (Fig. 2). Out of 33 patients who received glycopyrrolate, $31(93.9 \%)$ patients received $0.2 \mathrm{mg}$ whereas $2(6.1 \%)$ patients received $0.1 \mathrm{mg}$.

Out of 10 patients who received fentanyl, 3 (6.12\%) patients underwent exploratory laparotomy for intestinal obstruction and 2 (4.08\%) for perforation peritonitis. One patient undergoing bowel gangrene, perforation, perforation peritonitis with a strangulated incisional hernia, gastroschisis, and malignant ovarian tumor each received fentanyl.

\section{DISCUSSION}

Use of pre-anesthetic medicines for facilitation of surgery and decrease the risk of surgery-related complications is a common practice worldwide. There may be geographical variations in the pattern of pre-anesthetic medicine usage. In this study, we report the usage of pre-anesthetic medications in patients with exploratory laparotomy performed for various indications over the period of 6 months.

The study population was predominantly adult patients. The mean \pm SD age of patients was $65.85 \pm 34.15$ years. The study included two babies; one of 3 days and other of 15 days. Perforation peritonitis was the most common indication for exploratory laparotomy in this study. Male population dominated the study population. Almost two-third study population was male. Separate gender-wise analysis may provide some valuable insights regarding indications for exploratory laparotomy.

Post-operative nausea and vomiting are the common problems in patients undergoing surgical procedures [10,13-15]. Risk of acid aspiration is another concern in patients undergoing surgery under general anesthesia [16]. Pre-anesthetic medicines are used to reduce gastric acid and volume of gastric secretion, increase gastric $\mathrm{pH}$ and reduce the risk of nausea and vomiting $[13,16]$. Ranitidine given is more effective than proton pump inhibitors in reducing volume of gastric secretion and increasing gastric $\mathrm{pH}$ [16]. Another prospective, randomized, double-blind study showed that intravenous prophylactic ranitidine and metoclopramide is useful to reduce the volume of gastric content and increase gastric $\mathrm{pH}$ [11]. In our study, use of ranitidine and metoclopramide injection was very common, and ondansetron, a 5 HT3 antagonist $[17,18]$ was given to all patients undergoing exploratory laparotomy.

Pre-operative intravenous administration of pentazocine is useful to reduce intraoperative hemodynamic changes and post-operative pain [9]. We observed common use of pentazocine as a pre-anesthetic medication for exploratory laparotomy. As pre-surgical period is often associated with stress, fear, and anxiety [19-21]. Benzodiazepines are commonly used as pre-anesthetic medications to reduce anxiety [19]. In a retrospective study from India, alprazolam was the most commonly used anti-anxiety benzodiazepine [19]. In our study, midazolam was the preferred. It is used as pre-anesthetic medication in adults as well as children [19,21].

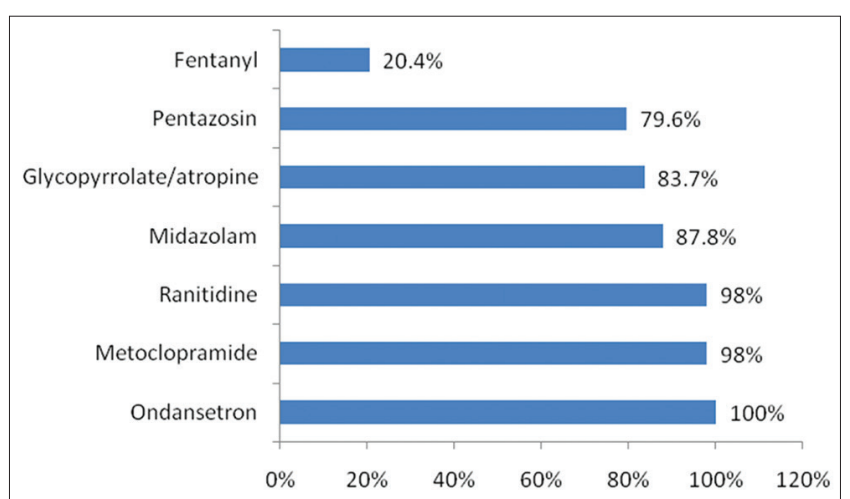

Fig. 1: Pre-anesthetic medications used in the study $(n=49)$

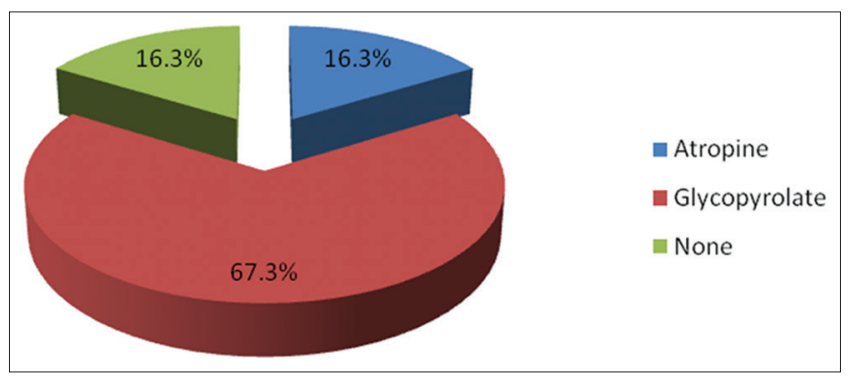

Fig. 2: Usage of anticholinergic agents as pre-anesthetic medication $(n=49)$

In an old survey, anticholinergic premedication use was reported in $36 \%$ and $56 \%$ of adults and children, respectively. The results showed atropine and hyoscine to be the most commonly used anticholinergic drugs [22]. In our study, 83.7\% patients received either glycopyrrolate or atropine. Glycopyrrolate is more potent than atropine [5]. Glycopyrrolate was the preferred anticholinergic agent in our study as evidenced by its more than 4 times use compared to atropine.

Use of short-acting opioids such as fentanyl for the management of postoperative pain and reduction of surgical stimulation during anesthesia management is common [23]. We observed a considerable difference in the usage pattern of fentanyl in patients undergoing exploratory laparotomy. Although 19 patients underwent exploratory laparotomy for perforation peritonitis, only two of them received fentanyl. Similarly, nine patients underwent surgery for intestinal obstruction, but three received fentanyl. We feel that the reasons for the use of fentanyl may be related to the severity of pain.

Our study results provide useful insights regarding the use of preanesthetic medicines in a tertiary care center. However, our study has some imitations. Considering small sample size, cross-sectional retrospective study design and single center data, observations of our study should be carefully extrapolated. 


\section{CONCLUSION}

The major pre-anesthetic medications used in patients undergoing exploratory laparotomy include ondansetron, metoclopramide, ranitidine, midazolam, glycopyrrolate, and pentazocine. Glycopyrrolate is the most preferred anticholinergic agent in these patients.

\section{AUTHOR'S CONTRIBUTIONS}

Dr. Madhuri Kulkarni conceptualized the study, collected data, assisted in statistical analysis and writing manuscript. Dr. Anant Patil performed literature, Search, statistical analysis of the data and wrote the manuscript.

\section{CONFLICT OF INTEREST}

None.

\section{REFERENCES}

1. Sheen MJ, Chang FL, Ho ST. Anesthetic premedication: New horizons of an old practice. Acta Anaesthesiol Taiwan 2014;52:134-42.

2. Suri Y. Evaluation of midazolam and diazepam for pre-operative sedation. Med J Armed Forces India 2000;56:287-92.

3. Wong HY, Fragen RJ, Dunn K. Dose-finding study of intramuscular midazolam preanesthetic medication in the elderly. Anesthesiology 1991;74:675-9.

4. Kain ZN, Caldwell-Andrews AA, Krivutza DM, Weinberg ME, Wang SM, Gaal D, et al. Trends in the practice of parental presence during induction of anesthesia and the use of preoperative sedative premedication in the united states, 1995-2002: Results of a follow-up national survey. Anesth Analg 2004;98:1252-9, table of contents.

5. Kongsrud F, Sponheim S. A comparison of atropine and glycopyrrolate in anaesthetic practice. Acta Anaesthesiol Scand 1982;26:620-5.

6. Rautakorpi P, Manner T, Kanto J. A survey of current usage of anticholinergic drugs in paediatric anaesthesia in finland. Acta Anaesthesiol Scand 1999;43:1057-9.

7. Rajendra N, Raj A, Madhusudhana R, Das P, Krishnamurthy D. Anaesthetic management of a patient with previous lobectomy posted for emergency modified radicle mastoidectomy. Int J Pharm Pharm Sci 2016;8:305-6

8. Ali Q, Hu Y, Wang Y, Wu S, Qin Z, Wang J, et al. Pentazocine pretreatment suppresses fentanyl-induced cough. Pharmacol Rep 2010;62:747-50.
9. Wang N, Wang L, Gao Y, Zhou H, Wang J. Analgesic effect of preoperative pentazocine for laparoscopic cholecystectomy. Cureus 2016;8:e948.

10. Gupta P, Jain S. Postoperative nausea and vomiting prophylaxis: A comparative study of ondansetron, granisetron and granisetron and dexamethasone combination after modified radical mastectomy. Saudi J Anaesth 2014;8:S67-71.

11. Hong JY. Effects of metoclopramide and ranitidine on preoperative gastric contents in day-case surgery. Yonsei Med J 2006;47:315-8.

12. Kulkarni M, Patil A. A cross-sectional pharmacoepidemiological study of the utilization pattern of pre-anesthetic medications in major surgical procedures in a tertiary care hospital. Cureus 2017;9:e1344.

13. Jain R, Sharma R. A comparative study of effects of glycopyrrolate and ondansetron on nausea and vomiting in cesarean section under spinal anesthesia. Anesth Essays Res 2015;9:348-52.

14. Mihara T, Tojo K, Uchimoto K, Morita S, Goto T. Reevaluation of the effectiveness of ramosetron for preventing postoperative nausea and vomiting: A systematic review and meta-analysis. Anesth Analg 2013;117:329-39.

15. Fujii Y. Prophylaxis of postoperative nausea and vomiting in patients scheduled for breast surgery. Clin Drug Investig 2006;26:427-37.

16. Clark K, Lam LT, Gibson S, Currow D. The effect of ranitidine versus proton pump inhibitors on gastric secretions: A meta-analysis of randomized control trials. Anaesthesia 2009;64:652-7.

17. Cohen IT. An overview of the clinical use of ondansetron in preschool age children. Ther Clin Risk Manag 2007;3:333-9.

18. Altannak NF. Comparative LC-MS stability indicatind assays of ondansetron hydrochloride/naloxone hydrochloride and metoclopramide/naloxone hydrochloride used in palliative care. Int J Pharm Pharm Sci 2015;7:109-13.

19. Biswas P, Niveditha, Shivamurthy MC. A study to evaluate the pattern of preanaesthetic medication in various surgical specialties in a tertiary care hospital. Int J Pharm Sci Res 2014;5:2441-6.

20. Ruhaiyem ME, Alshehri AA, Saade M, Shobi TA, Zahoor H, Tawfeeq NA. Fear of going under general anesthesia: A cross-sectional study. Saudi J Anaesth 2016;10:317-21

21. Ghali AM, Mahfouz AK, Al-Bahrani M. Preanesthetic medication in children: A comparison of intranasal dexmedetomidine versus oral midazolam. Saudi J Anaesth 2011;5:387-91.

22. Mirakhur RK. Preanaesthetic medication: A survey of current usage. J R Soc Med 1991;84:481-3.

23. Lim H, Doo AR, Son JS, Kim JW, Lee KJ, Kim DC, et al. Effects of intraoperative single bolus fentanyl administration and remifentanil infusion on postoperative nausea and vomiting. Korean J Anesthesiol 2016;69:51-6. 